\title{
PERANCANGAN MEDIA VIDEO INTERIOR BERBENTUK ANIMASI DENGAN MENGGUNAKAN 3DS MAX
}

\author{
Wahyu Hidayat ${ }^{1}$ \\ Wahyu Hidayat ${ }^{2}$ \\ Farhan Rachmatullah ${ }^{3}$ \\ e-mail : Wahyu@raharja.info,WahyuHidayat@raharja.info,farhan.thespokat@gmail.com
}

\author{
Diterima : 16 Januari 2014 / Disetujui : 25 Januari 2014
}

\begin{abstract}
Interior design and decoration for this often happens in common where they like in a the same profession. Becausethey both have the same goal, namely to provide a sense of beauty and comfort in any room. The Interior decoration is only a small part of his task an interior designer.Interior dandekorator interior designers are equally important in samamemilikiperan to improve the quality of the room, although both are different. As for the field that will be needed at a company or organization to design a media campaign in promoting and informing a product item or service to the community. So the company becomes taxable in the community and in promoting a product or a simulation of the design you want. To promote it field examples like design, Interior, Multimedia, and animations.
\end{abstract}

Keywords: Design, Decoration, Interior, Animation

\begin{abstract}
ABSTRAKSI
Desain Interior dan dekorasi selama ini sering terjadi kesamaan dimana keduanya seperti dalam suatu profesi yang sama. Karena keduanya sama-sama memiliki yang sama yaitu ingin memberikan rasa rasa keindahan dan kenyaman di setiap ruangan. Dekorasi Interior hanya bagian kecil dari tugasnya seorang desainer interior.Desainer interior dan dekorator
\end{abstract}

1. Dosen Jurusan Sistem Informasi, STMIK Raharja

Jl. Jend Sudirman No. 40 Modern Cikokol-Tangerang Telp. 5529692

2. Dosen Jurusan Sistem Informasi, STMIK Raharja

Jl. Jend Sudirman No. 40 Modern Cikokol-Tangerang Telp. 5529692

3. Mahasiswa Jurusan Sistem Informasi, STMIK Raharja

Jl. Jend Sudirman No. 40 Modern Cikokol-Tangerang Telp. 5529692 
interior sama-sama memiliki peran yang penting dalam meningkatan kualitas ruangan, meskipun keduanya berbeda. Adapun bidang ini yang nantinya akan diperlukan pada suatu perusahaan atau organisasi untuk mendesain sebuah media promosi dalam mempromosikan dan menginformasikan suatu produk barang atau jasa kepada masyarakat.Sehingga perusahaan tersebut menjadi di kena oleh masyarakat dan di promosikan suatu produknya atau simulasi dari desain yang inginkan. Bidang untuk mempromosikannya contohnya seperti desain, Interior,Multimedia, dan Animasi

Kata Kunci: Design, Dekorasi, Interior,Animasi

\section{PENDAHULUAN}

Saat ini perkembangan teknologi sudah sangat maju, kemampuan dalam hal teoritis di bidang komputer saja belum tentu cukup untuk mengikuti perkembangan zaman tersebut, dan sampai saat ini terdapat terobosan-terobosan baru dimana komputer menjadi hal yang tidak terpisahkan dari kebutuhan sehari hari sehingga membuat integrasi antar berbagai disiplin ilmu seperti desain grafis, broadcasting dan audio-visual. Ditandai dengan munculnya berbagai macam bentuk karya seni yang menggunakan aplikasi komputer sebagai sarana perencanaan dan perancangan sebuah karya, contohnya: film dokumenter, profile film feature biografi seseorang, iklan, Interior design, Animasi dan berbagai bentuk rancangan komunikasi visual lainnnya. Hal ini dibuktikan bahwa perancangan suatu karya seni meningkat lebih baik, sehingga dapat mengikuti tuntutan perkembangan teknologi yang begitu pesat. Sarana multimedia dan design sebagai alat komunikasi dan promosi mempunyai peranan yang sangat penting dalam menginformasikan sesuatu kepada masyarakat, hal ini dinilai sangat komunikatif dan efektif disaat mobilitas manusia yang semakin tinggi sehingga dibutuhkan bentuk media komunikasi dan promosi yang menarik dan lebih interaktif yang ditujukan kepada masyarakat, dan banyak cara untuk menyampaikan suatu informasi yang diolah ke dalam bentuk multimedia dan design agar terlihat lebih menarik dalam penyampaiannya.

PT.Utama Mandiri Jaya adalah perusahaan yang mempunyai motto kepuasan adalah kebanggan kami PT. Utama Mandiri Jaya. Berlokasi di jl.JendralSudirman no 63 Cikokol Tangerang. PT. Utama Mandiri Jaya didirikan di Tangerang pada tahun 2005, oleh Sadeli, didasari oleh adanya kebutuhan masyarakat akan papan atau produk furniture dan peluang usaha yang cukup menjanjikan pada saat itu, dimana pada awalnya banyak permintaan sehingga semakin memantapkan PT.UtamaMandiri Jaya ini melebarkan sayap dan menambah alat-alat dan jumlah 
pekerja yang dibutuhkan. Saat ini PT.UtamaMandiri Jaya, menggunakan media promosi dan informasi dalam bentuk media cetak saja yaitu masih berupakatalog,terakhir pembuatan pada tahun 2010 dan melakukan presentasi ke klien secara lisan, melakukan pemasaran dengan memperlihatkan foto-foto dan fasilitas yang belum di kemas dalam bentuk gambaryang sudah rapi dan terorganisir dengan baik, dan semakin berkembangnya perusahaan setiap tahunnya, kebutuhan perusahaan akan promosi akan terus bertambah sesuai perkembangan zaman.Dalam mengembangkan usahanya saat ini PT.UtamaMandiri Jaya, sangat membutuhkan sarana media penyampaian informasi dan promosi yang mampu mengemas seluruh aset yang dimiliki perusahaan dalam menjalin relasi atau kerjasama baik dengan klien perseorangan, klien perusahaan, instansi atau lembaga terkait.Dari hasil analisa kebutuhan yang dilakukan penulis terhadap PT.UtamaMandiri Jaya, perusahaan tersebut membutuhkan media promosi yang menarik untuk memperkenalkan seluruh produkdan diharapkan melalui perancangan media komunikasi visual ini dapat meningkatkan omset perusahaan.

\section{MEDIA VIDEO INTERIOR BERBENTUK ANIMASI}

\section{a. Pengertian Interior}

Menurut Ching, interior sebuah bangunan dibentuk oleh elemen-elemen arsitektur dari struktur dan pembentuk ruangnya yang terdiri atas kolom, dinding, lantai, dan plafon. Elemen-elemen tersebut memberi bentuk pada bangunan, memisahkannya dengan ruang luar, dan membentuk pola tatanan ruang interior (Ching, 2010: 160). Sementara itu, Suptandar (2010: 1) mengatakan bahwa interior adalah ruang dalam atau bagian dalam bangunan, apapun, dan bagaimanapun bentuk bangunan tersebut. Berdasarkan uraian di atas diketahui bahwa interior berhubungan dengan ruang. Ruang merupakan unsur terpenting dalam desain sebagai tempat bagi manusia Untuk melakukan aktivitasnya, selain sebagai tempat tinggal, harga diri, dan lambang status sosial (Suptandar, 2010: 62). Jadi dapat disimpulkan bahwa interior adalah ruang dalam sebuah bangunan yang dibentuk oleh elemen-elemen arsitektur dari struktur dan pembentuk ruangnya, apapun dan bagaimanapun bentuknya yang merupakan unsur terpenting dalam desain sebagai tempat bagi manusia melakukan segala aktivitasnya.

\section{b. Visualisasi 2D dan 3D}


Visualisasi 2 dimensi yang lebih dikenal dengan2D atau bidang adalah bentuk dari benda yang memiliki panjang dan lebar.Penggambarannya padalayar (monitor) dilakukan dengan berpatokan pada titik koordinat sumbu x (datar) dan sumbu y (tegak).Koordinat tersebut dihitung mulai dari sudut kiri atas layar.Semakin kekanan, nilai koordinat $x$ semakin bertambah.Semakin kebawah, nilai koordinat y semakin bertambah.Besarnya nilai koordinat ini dihitung dalam satuan pixel.Agar dapat tampil dengan sempurna, gambar yang akan ditampilkan dengan teknik ini harus memiliki nilai koordinat $\mathrm{x}$ dan y minimum 0 dan maksimum sebesar resolusi yang digunakan.Visualisasi 3 dimensi yang dikenal dengan 3D atau ruang adalah bentuk dari benda yang memiliki panjang, lebar dan tinggi dantinggi.Grafik 3 Dimensi merupakan teknik penggambaran yg berpatokan pada titik koordinat sumbux (datar), sumbu y (tegak), dan sumbu z (miring). Representasi dari data geometrik 3 dimensi sebagai hasil dari pemrosesan dan pemberian efek cahaya terhadap grafika komputer 2D.Tiga Dimensi (3D) biasanya digunakan dalam penanganan grafis. 3D secara umum merujuk pada kemampuan dari sebuah video card (link). Saat ini video card menggunakan variasi dari instruksi-instruksi yang ditanamkan dalam video card itu sendiri (bukan berasal dari software) untuk mencapai hasil grafik yang lebih realistis dalam memainkan game komputer.Grafik komputer 3D juga merupakan representasi dari data geometrik 3 dimensi sebagai hasil dari pemrosesan dan pemberian efek cahaya terhadap grafika komputer 2D.Hasil ini kadang kala ditampilkan secara waktu nyata (real time) untuk keperluan simulasi. Secara umum prinsip yang dipakai adalah mirip dengan grafika komputer 2D, dalam hal: penggunaan algoritma, grafikavektor, model frame kawat (wire frame model), dan grafikarasternya.

Grafik komputer 3D merupakan suatu grafis yang menggunakan 3 titik perspektif dengan cara matematis dalam melihat suatu objek, di mana gambar tersebut dapat dilihat secara menyeluruh dan nyata. Untuk perangkat-perangkat lunak yang digunakan untuk grafik komputer 3D ini banyak bergantung pada algoritma-algoritma. Grafika komputer 3D sering disebut sebagai model 3D. Namun, model 3D ini lebih menekankan pada representasi matematis untuk objek 3 dimensi. Data matematis ini belum bisa dikatakan sebagai gambar grafis hingga saat ditampilkan secara visual pada layar komputer atau printer. Proses penampilan suatu model matematis ke bentuk citra $2 \mathrm{D}$ biasanya dikenal dengan proses 3D rendering.

\section{c. Unsur - unsur Desain Interior}

Suptandar, (2010: 70). Unsur-unsur adalah alat atau bahan baku seperti cat adalah dasar-dasar untuk seorang pelukis. Unsur-unsur desain termasuk ruang garis 
bentuk warna dan tekstur. Prinsip-prinsip desain yang berhubungan dengan bagaimana Anda menggunakan elemen-elemen dan keseimbangan penekanan irama proporsi dan skala dan harmoni dan persatuan.

\section{METODOLOGI PENELITIAN}

Pelaksanaan penelitian yang penulis lakukan, Adalah melakukan beberapa metode pengumpulan data diantaranya:

\section{a. Metode Analisa Masalah}

Analisa permasalahan didapatkan dari hasil interview yang dilakukan penulis pada hari senin 14 Agustus 2013 ke PT.UtamaMandiri Jaya dengan Bapak Bram Persada sebagai pengelola dari PT.UtamaMandiri Jaya.

\section{b. Metode Pengumpulan Data}

Pengumpulan data dilakukan dengan cara :

- Metode Observasi

Metode yang dilakukan penulis untuk mengumpulkan data dan mendapatkan hal-hal yang diperlukan dalam proses penyusunan laporan penilitian dengan cara mendatangi tempat penelitian secara langsung.

- Metode Interview

Materi-materi yang dipergunakan dalam penyusunan laporan penelitian ini diperoleh dengan bertanya langsung dengan stakeholder Bapak Bram Persadapada PT. UtamaMandiri Jaya.

- Studi pustaka

Materi-materi yang dipergunakan sebagai dasar landasan diperoleh dari berbagai sumber tertulis, yaitu buku-buku panduan yang terkait dan memuat informasi-informasi yang diperlukan untuk digunakan dalam penyusunan laporan penelitian. Buku-buku panduan yang dipergunakan penulis dalam hal ini adalah dari berbagai sumber.

\section{c. Metode Analisa Perancangan Media}

Perancangan media komunikasi visual sebagai penunjang media promosi dan informasi dirancang berdasarkan analisa terhadap media yang telah digunakan pada media sebelumnya, selain dari itu juga terhadap analisa kebutuhan yang diajukan kepada stakeholder, selanjutnya dirancang dengan menggunakan aplikasi program komputer grafis.Media-media yang akan dipergunakan sebagai sarana penunjang 
promosi PT.UtamaMandiri Jaya dirancang dengan menggunakan aplikasi Autodesk 3ds Max 2010 dan proses editing dengan Adobe Premiere CS 3.

\section{d. Metode Konsep Desain}

Dalam konsep desain akan disampaikan tahapan-tahapan proses desain media yaitu:

- Perencanaan Media

- Perencanaan Pesan

- Perencanaan Visual

\section{HASIL DAN PEMBAHASAN}

\section{a. Literatur Review}

Penelitian yang dilakukan oleh Penulis berjudul "Perancangan Media Video Interior Berbentuk Animasi Dengan Menggunakan 3ds Max Pada PT. Utama Mandiri Jaya”. Iklan merupakan pesan yang menawarkan suatu produk yang ditujukan oleh suatu masyarakat lewat suatu media. Dan setelah penulis melakukan analisa terhadap permasalahan yang ada maka terwujudlah sebuah usulan kepada Perguruan Tinggi Raharja untuk membuat sebuah media iklan, yaitu suatu karya desain yang dikemas dalam bentuk audio visual yang merupakan sebagai media promosi untuk menarik minat masyarakat untuk menjadi Pribadi Raharja.

\section{b. Implementasi}

1) Implementsi Yang Diusulkan Media Video Interior Berbentuk Animasi Dengan Menggunakan 3ds Max Pada Pt.Utama Mandiri Jaya”.

\section{a. Logo PerguruanTinggiRaharja}

Logo PerguruanTinggiRaharja yang bergerak berputar putar dan tersusun kemudian jadi berbentuk logo Perguruan Tinggi Raharja.

Cara Pembuatannya :

1. Bukalah aplikasi Autodesk 3Ds Max

2. Setelah itu menuju ke lembar kerja dan terdapat 4 lembar kerja yaitu :

- Top : Tampak atas

- Front : Tampak depan

- Left : Tampak samping 
- Perspective : Tampak bebas

3. Lalu buat logonya menjadi terpisah pisah dan pertama-tama membuat garis terlebih dahulu pilih shape+Line dan ngepath membentuk logo

4. Kemudian pilih modify dan pilih extrude Dan akan menjadi seperti ini

5. Lalu pilih geometry dan klik cylinder, Box dan line untuk buat logonya buat secara terpisah-pisah

6. Kemudian membuat tulisan Perguruan tinggi raharja dengan text di Splines dan di extrude seperti no 4

7. Buat tulisannya menjadi melengkung dengan memilih modify dan cari Bend dan buat bintangnya menggunakan line seperti no $3 \mathrm{~b}$.

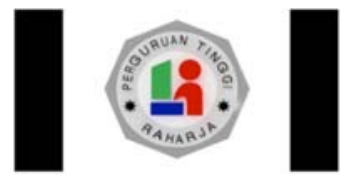

\section{b. Sket Gambar Openning Tulisan Nama Penulis, Nim dan MAVIB}

Sket gambar opening tulisan Nama Penulis,Nim dan MAVIB (Multimedia Audio Visual and Broadcasting) yang diberi animasi bergerak di mulai dari malam kemudian siang dan bergerak lurus kedepan menampilkan Nama Penulis, Nim dan MAVIB( Multimedia Audio Visual and Broadcasting ). Sket opening tulisan Nama Penulis, Nim dan MAVIB

\section{Cara Pembuatannya :}

Sebelum membuatnya pertama-tama kita harus mengerti tentang Topology modeling dan bisa di pelajari banyak di youtube. Dan Membuat perahunya sama harus mengerti topology modeling untuk Mempercepat prosesnya download pluginnya aja yang perahu dan pohon di situs http://archive3d.net/

1. Buat modelingnya pulaunya terlebih dahulu dengan menggunakan topology modeling. Bisa buat dari box atau cylinder sesuai dengan keinginan.

2. Kemudian klik kanan di mouse terus pilih convert to lalu pilih conver to editable poly.

3. Lalu kita membuat garis topology dengan mengklik objek dan memilih line dan klik Ring untuk membuat garis topology klik F3 untuk lebih memperjelas garis topologynya dan klik kanan pilih connect.

4. Kemudian Pilih polygon kotak yang berwarna merah dan klik kanan di objek 
dan pilih extrude sehingga menjadi seperti ini

5. Untuk memperhalus dari objek tersebut pilih modivy dan pilih turbo smooth.

6. Kemudian membuat semuanya sama seperti no5 kita hanya memainkan topology modelingnya.

7. Kemudian kita import dari hasil plugin perahunya dengan cara file dan import file pilih formatnya 3ds atau obj.

8. Setelah semuanya di buat modelingnya dan akhirnya menjadi seperti di bawah ini lalu akan di animasikan dengan menggunakan camera buatan yang terdapat di software 3D smax

9. Selanjutnya keproses animasinya pilih timeline untuk menentukan berapa durasi dari animasi tersebut dengan perframe, 30 frame gambar adalah 1 detik terlebih dalu klik Auto key untuk merekam animasi tersebut dari klik kameranya dan majukan kameranya dengan menarik garis merah,hijau,biru rekam sesuai keinginan.

10. Proses render klik F10 dan pilih commond dan pilih Asign Renderer dan pilih mental ray

11. Setelah di Animasikan dengan menggunakan kamera lalu save rendernya dengan klik rendering dan pilih bact render dan di render akan menghasilkan beberapa frame gambar sesuai timeline angka animasi yang di buat.

12. Setelah itu Klik Add, ceklist Override present, Klik Output Path untuk mengesave dimana hasil render perframenya dan pilih camera dan klik render.

13. Sehingga akan menjadi seperti ini bila di render.

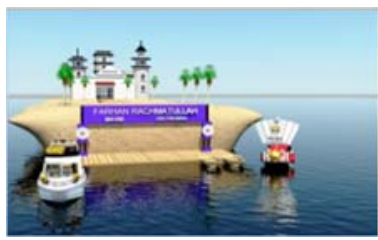

\section{c. Isi Program Animasi Interior Desain}

Isi program Animasi Interior Desain yaitu diawali dengan gambar depan Rumah salah satu pelanggan dari PT. Utama Mandiri Jaya, setelah itu terlihat tulisan PT. Utama Mandiri Jaya yang di Animasikan dari 3DSMAX .Setelah itu langsung kesket video atau beberapa potongan-potongan (cut to cut) dari Interior Ruangan dari jasa PT. Utama Mandiri JayaTulisan PT. UtamaMandiri Jaya Potongan (cut to cut) gambar 


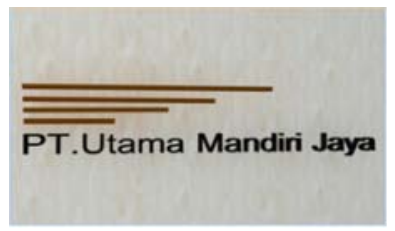

Tulisan PT. UtamaMandiri Jaya
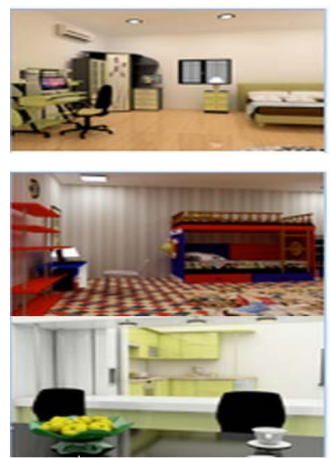

Potongan (cut to cut) gambar

\section{d. Proses Pembuatan Design}

\section{Logo Animasi Perguruan Tinggi Raharja}

Dalam proses pembuatan animasi logo Perguruan Tinggi Raharja, diawal idengan proses pengeditan gambar logo dengan menggunakan aplikasi Autodesk 3Ds Max di render dan menghasilkan beberapa frame dengan format penyimpanan file *png, setelah itu dilanjutkan dengan proses penyatuan gambar per frame menjadi sebuah animasi dengan menggunakan aplikasi Adobe After Effect, efek animasi yang digunakan adalah bentuk logo terpisah dan berputar-putar sehingga membentuk sepenuhnya logo Perguruan Tinggi Raharja. Logo Perguruan Tinggi Raharja
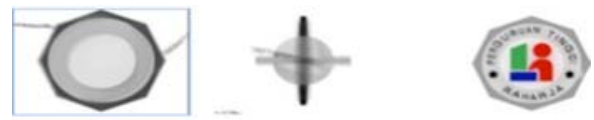

Logo PerguruanTinggi Raharja 


\section{PembuatanOpenning (bummper) Animasi}

Dalam pembuatan opening animasi terdapat NamaPenulis, Nim dan MAVIB (Multimedia Audio Visual and Broadcasting) yang diberianimasi bergerak di mulai dari malam kemudian siang dan bergerak lurus kedepan menampilkan Nama Penulis, Nim dan MAVIB ( Multimedia Audio Visual and Broadcasting ). Tulisan Bumper Animasi NamaPenulis, Nim, dan MAVIB.
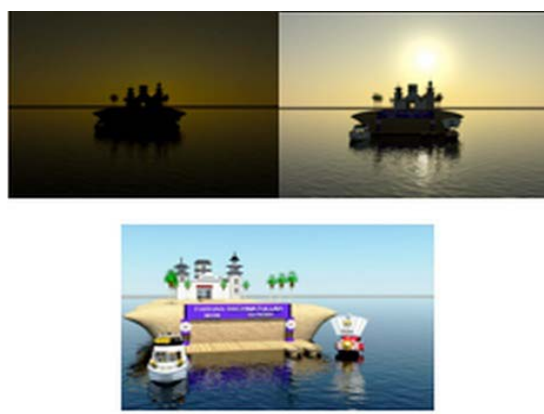

Tulisan Bumper AnimasiNamaPenulis, Nim, dan MAVIB

\section{Proses Produksi Isi Sebuah Animasi Interior Desain}

Proses produksi isi sebuah Animasi Interior Desain yaitu memperlihatkan potongan-potongan video (cut to cut) dari depan rumah dari salah satu pelanggan perusahaan tersebut dan masuk ke dalam rumah dan memperlihatkan interior ruangannya. Pada proses ini seluruh pembuatan animasi mengunakan software Autodesk 3Ds Max dan proses editing animasinya dilakukan dengan menggunakan software Adobe Premiere cs 3 untuk pengeditan sebuah Animasi, dan didalam software ini semua penggabungan gambar di lakukan pada software Adobe Premiere cs 3, sehingga menjadi suatu video yang masih mentah. Pada awal gambar yang ditayangkan adalah gambar yang telah di render dari software 3Ds Max , yaitu menggambarkan suasana interior desain pada ruangan yang ada di rumah.

\section{Pembuatan Storyboard}

Storyboard merupakan visualisasi rekaan yang berbentuk sketsa gambar seperti perkiraan hasil gambar yang nantinya akan di jadikan pedoman pengambilan gambar oleh kamera yang berada di software Autodesk 3Ds Max. 
gambar ini dibuat oleh Penulis. Dalam media animasi interior desain ini storyboard yang dipergunakan adalah beberapa frame gambar animasi yang telah di render menjadi video, adalah sebagai berikut:
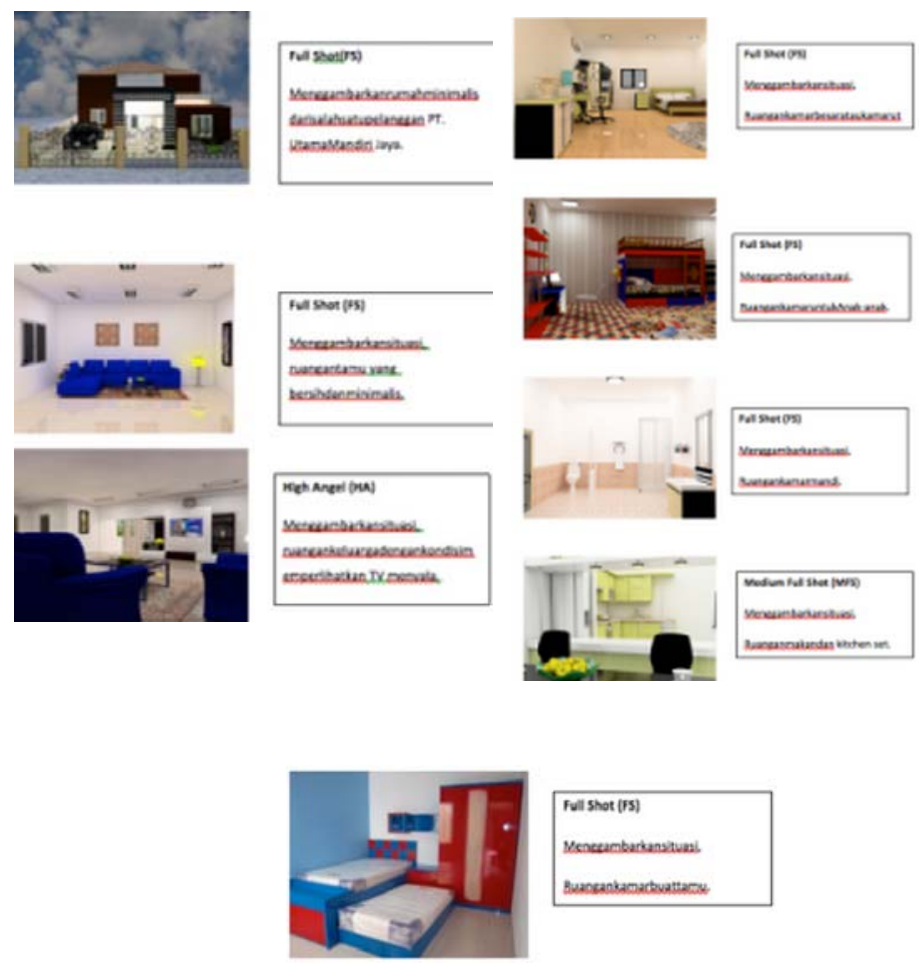

5. Hasil Produksi Animasi Interior Desain Dan Finnishing

Proses ini adalah penyelesaian dari sebuah Animasi Interior Desain dan ditujukan untuk melihat apakah produksi Animasi ini telah sesuai dengan apa yang telah dikonsepkan, sebelum diperlihatkan kepada audience.

\section{e. Konfigurasi Hardware}

\section{Perangkat Keras Yang Dibutuhkan}

Perancangan Katalog tersebut menggunakan 1 unit komputer dengan spesifikasi sebagai berikut :
a. Processor : core i7
b. Monitor : LED 21 inc 

c. Mouse : Optik
d. RAM : $8 \mathrm{~Gb}$
e. Harddisk : $1 \mathrm{~Tb}$
f. Keyboard : International Layout
g. Printer : Inkjet Printer

\section{KESIMPULAN}

Setelah penulis melakukan penelitian pada PT. UtamaMandiri Jaya, penulis berkesimpulan bahwa Media Animasi Interior dessain yang dikemas dalam bentuk Audio Visual (Video) sangat di perlukan bagi PT. UtamaMandiri Jaya khususnya di bidang propeti, kitchen set juga interior desain,dan dengan adanya Media Animasi Interior desain tersebut dapat meningkatkan suatu image atau citra dari masyarakat agar tertarik dengan produk dari PT. Utama Mandiri Jaya.Dalam pembuatan media Animasi Interior desain yang baik, harus memperhatikan faktor-faktor yang berhubungan dengan PT. UtamaMandiri Jaya yang bersangkutan.Dalam hal ini penulis menyesuaikan dengan keinginan stakeholder, mulai dari pembuatan Animasi, tampilan, isi pesan dan penutup.Hal ini bertujuan untuk memperkuat media Animasi audio viual (video) dalam mempromosikan Produk interior desain dan mengajak masyarakat untuk dapat berlangganan dan menjadi pelanggan tetap dari PT. Utama Mandiri Jaya.

\section{DAFTAR PUSTAKA}

[1] Hendratman, Hendi, Konsep Dasar Perancangan Interior, Jakarta, 2009.

[2] Rumpak, Julius C, Definisi Informasi dan Promosi Animasi , 2010.

[3] Kadir, Abdul, Definisi Data desain, Jakarta, 2011.

[4] Sutanta, Edhy, Media Informasi animasi, Bandung, 2010.

[5] Wahyono, Teguh, Media InformasiManajemen, 2012.

[6] Purbo, Ono W, Quality of Information, 2011

[7] Ching,Suptandar,Pengertian Interior, 2010.

[8] Tjiptono, Fandi, Jenis-jenis Media interior desain, 2009.

[9] Noe'man, Irvan A, Drawing and Illustration for Graphic Design, 2010

[10] Susanto, Mike, BelajarDesain, 2011.

[11] Kuswara,Interior Desain, 2009.

[12] Petra Christian University Library Online catalog, 2009 “ Interior kelenteng 
“,Skripsi pada Universitas Kristen Petra Jakarta.

[13] Suprapto, Tommy, Berkarier di bidang Broadcasting, Media Pressindo, Yogyakarta, 2010. 